\title{
Survival Outcomes of Breast Cancer in Ghana: An Analysis of Clinicopathological Features
}

\author{
Alice C. Mensah ${ }^{*}$, Joel Yarney², Sagary Kaku Nokoe³, Samuel Opoku4, J. N. Clegg-Lamptey5,6 \\ ${ }^{1}$ Mathematics and Statistics Department, Accra Polytechnic, Accra, Ghana \\ ${ }^{2}$ National Centre for Radiotherapy and Nuclear Medicine, Korle Bu Teaching Hospital, Accra, Ghana \\ ${ }^{3}$ Department of Mathematics, University of Energy and Natural Resources, Sunyani, Ghana \\ ${ }^{4}$ Department of Radiography, School of Health Sciences, University of Ghana, Accra, Ghana \\ ${ }^{5}$ Department of Surgery, University of Ghana School of Medicine and Dentistry, Accra, Ghana \\ ${ }^{6}$ Department of Surgery, Korle Bu Teaching Hospital, Accra, Ghana \\ Email: *alicecabakah@yahoo.com
}

Received 2 January 2016; accepted 19 January 2016; published 22 January 2016

Copyright (C) 2016 by authors and OALib.

This work is licensed under the Creative Commons Attribution International License (CC BY).

http://creativecommons.org/licenses/by/4.0/

(c) (i) Open Access

\section{Abstract}

Breast cancer is the most frequently diagnosed cancer and the leading cause of cancer death in female's worldwide. Its incidence is on the ascendancy in Africa including Ghana. In addition, Ghanaian women are more likely to be diagnosed with high-grade tumours that are triple negative breast tumours. The objectives of the study were to investigate the clinicopathologic features of breast cancer in Ghanaian women; identify and describe breast cancer survival pattern in Ghana and factors that explain the disparity in survival rates for breast cancer by the use of Cox proportional hazard. Two thousand three hundred and ninety seven (2397) women were sampled for the study from the Korle-Bu Teaching Hospital (KBTH), of which 1022 (42.64\%) were diagnosed with breast cancer between the periods $1^{\text {st }}$ January 2002 to $31^{\text {st }}$ December 2008. The cases were followed up to January 2011. It was found that Mean age for the cases was 47.97 years. The largest number of cases being 59.69\% was aged 40 - 49 years. Invasive Ductal Carcinoma (IDC) was $72.90 \%, 71.28 \%$ had lump size of $2-5 \mathrm{~cm}$. Axillary lymph node involvement was found in $90 \%$ of the women diagnosed with breast cancer. 5-year cumulative survival was $91.94 \%$ for stage $0 \& I$ and $15.09 \%$ for stage IV. Data relating to tumour grading were $92.07 \%$ for high grade 2 and 3 . Triple negative breast cancer was identified in $66.38 \%$ (77 out of 116) of the cases with complete information on Estrogen Receptor, Progesterone Receptor and HER2 status. Cumulative 5-year survival was 47.91. Survival rate was better for early staged presentation; lymph node involvement of less than $25 \%$ and tumour size of less than $5 \mathrm{~cm}$. The study reinforces the urgent need for improved screening techniques for early detection, and for an aggressive health education campaign to increase the awareness of women in Ghana about the potential risk of breast cancer and early detection by regular testing.

\footnotetext{
${ }^{*}$ Corresponding author.
}

How to cite this paper: Mensah, A.C., Yarney, J., Nokoe, S.K., Opoku, S. and Clegg-Lamptey, J.N. (2016) Survival Outcomes of Breast Cancer in Ghana: An Analysis of Clinicopathological Features. Open Access Library Journal, 3: e2145.

http://dx.doi.org/10.4236/oalib.1102145 


\title{
Keywords
}

\section{Breast Cancer, Hormone Receptors, Survival Analysis, Tumour Size, Clinicopathological Features, Diagnosing Stage, Cox Proportional Hazard}

\author{
Subject Areas: Epidemiology
}

\section{Introduction}

Breast cancer is a malignant tumour in the glandular tissues of the breast. It is the most common type of lifethreatening cancer, and the second most common cause of cancer-related deaths of women in the Western world [1]. In Ghana, breast cancer is now the most common malignant disease in women and accounts for the majority of cancer related deaths [2] [3]. In 1996, 12.8\% of all admissions for malignant neoplasms to the Korle Bu Teaching hospital were for breast cancer [4]. This alarming state of affairs is due to many myths and misconceptions about breast cancer. These include linking mastectomy to death, attributing spiritual and supernatural causes to the disease, denial and guilt [5]. Reported clinical cases from some sub Saharan African countries including Ghana indicate that breast cancer in indigenous black African women population is often aggressive with unfavourable prognostic features, including young age at presentation, advanced stage at diagnosis, large tumour size, high grade histologic subtypes and low rate of receptor positivity [6]-[10].

There are concerns about increasing rate of breast cancer among young people in Ghana. In addition to the fact that the incidence of the disease appears to be on the increase, late presentation with poor outcomes of treatment is the hallmark of breast cancer in most developing countries including Ghana [5]. It is also disturbing that the average age at diagnosis for breast cancer in Ghana is 46.29 years with a range of 26 to 80 years as compared to an average age of over 65 years in Europe and America [11]-[13]. Breast cancer is also an important contributor of mortality among women in developing countries like Ghana. The results of survival analysis for cancer patients have been widely presented and reported for different human sub populations of the globe [14] [15].

The American Cancer Society cancer facts and figures, report that $98 \%$ of women survive breast cancer if it is detected while it is $2 \mathrm{~cm}$ in diameter; $88 \%$ if it is detected while the tumour size is 2 to $5 \mathrm{~cm}$ and has spread to axillary lymph nodes; 76\% survive breast cancer if it is detected even over $5 \mathrm{~cm}$ in diameter and has not spread to axillary lymph node [16].

However, very few survival results at national level are available for the female population of Ghana. The statistical evidence about the survival of the breast cancer patients at the KBTH is scanty in the literature. Therefore, the study focused on identifying and describing breast cancer survival pattern in Ghana and also identifying and evaluating the factors that could explain the disparity in survival rates for breast cancer in Ghana.

Breast cancer mortality rate is much higher among sub-Saharan women as compared to women in western countries, even though the incidence is much higher in western women [17] [18]. Five-year relative survival rates, standardised to the International Cancer Survival Standard [19], were calculated for patients aged 15 - 99 years diagnosed during the year 1990-1994. Breast cancer survival rates varied from over $80 \%$ in North America, Sweden, Japan, Australia and Finland to less than $60 \%$ in Brazil and Slovakia and below $40 \%$ in Algeria. Most European countries including Scotland, England, Ireland and Wales, had rates in the 70\% - 79\% range [20]. In Europe, Office for National Statistics in 2005 reported that, breast cancer survival had improved over time and inter-country survival differences were reducing. However, survival in the UK is far from the best and much lower than reported in the US. The most recent breast cancer survival rates in England were for women diagnosed in 2001 to 2006. For this group of women, five-year relative survival was $82 \%$ compared with only 52\% thirty years earlier in the year 1971-1975, states [21]. The US department of health and human services (20092010), stated the five year survival rate was $91 \%$ and $78 \%$ among white women and African American women respectively, [22].

Although breast cancer may not be a priority to international aid organizations due to the enormity of other health concerns, up to $70 \%$ of women who are diagnosed with breast cancer in Ghana happen to be in the advanced stages of the disease, resulting in a higher mortality rate compared to high-income countries [23]. In addition, a study has shown that Ghanaian women are more likely to be diagnosed with high-grade tumors that are 
triple negative breast tumor [24]. Explanations for the delayed presentation among Ghanaian women have been traced to the cost of, and access to, routine screening mammography, lack of awareness, and cultural attitudes [24]. Harsh social stigma, fear of mastectomy or death, and the appeal of traditional healers over doctors have also been cited as some of the cultural reasons for late presentation of cases in Ghana [25]. Furthermore, women with breast cancer in Ghana describe a feeling of hopelessness and helplessness, largely due to their belief in fatalism, which contributes to denial as a means of coping [25].

\section{Methodology}

\subsection{Study Location}

The study was carried out at the Korle Bu Breast Clinic and the National Centre for Radiotherapy and Nuclear Medicine, both located in the Korle Bu Teaching Hospital (KBTH). KBTH is the leading national referral centre in Ghana receiving patients from across the country, but mostly from the southern part. The Radiotherapy Centre serves as the cancer centre for the hospital. The Breast clinic, run by a multidisciplinary team, receives referrals but is a walk-in clinic that admits women who desire to be screened for breast cancer without a formal referral.

\subsection{Study Design}

This was a retrospective cohort study of all Ghanaian women who reported at the Breast Clinic of the Korle Bu Teaching Hospital (KBTH) and its cancer centre between January 2002 and December 2008.

\subsection{Data Source}

A questionnaire was used to collect data from patients' medical files from the Records Section of the Cancer centre of the KBTH. See Appendix A (Table A2) for sample schedule used in the data collection. Six variables for prognostic factors were investigated stage at diagnosis, tumour grade, tumour size, axillary node status, age at diagnosis, Estrogen Receptor (ER), Progesterone Receptor (PR) and Human Epidermal growth factor Receptor 2 (HER2) status. The time (measured in months) to the death was used for the survival analysis.

\subsection{Inclusion and Exclusion Criteria}

All Ghanaian women who visited the National Centre for Radiotherapy and Nuclear Medicine and the walk-in clinic for breast screening were eligible. Cases were required to have histologically proven breast cancer.

Patients with incomplete information, other malignancies (e.g. sarcomas) and aged less than twenty (20) years were excluded.

\subsection{Statistical Analysis}

Descriptive statistics of frequencies and percentages was used to describe the categorical variables. Patients' lifetime was calculated by month (the time span from day of diagnosis to death or termination of follow-up visit. Data was analysed by SAS version 9.0 (Cary, NC 27513 USA). p-value $<0.05$ was considered significant. The survival rate was calculated by Kaplan Meier method. All indexes of survival rate difference were analyzed by multiple factor Cox proportional hazard model.

\subsection{Ethical Standards}

This research has been assessed and approved by the School of Allied Health Sciences, University of Ghana Ethics and Protocol Review Committee with identification number: SAHS-ET./AA/1A/2013-2014.

Patients consent was not sought, but the study was granted a waiver for informed consents by the committee, due to the nature of the study and likelihood that many of the patients whose information we studied were now deceased or lost to follow-up.

\section{Results}

\subsection{Demographic Characteristics}

Two thousand three hundred and ninety seven (2397) women were sampled for the study, of which 1022 
(42.64\%) were diagnosed with breast cancer. Mean age was 47.97 years, see Appendix A (Table A1). Five hundred and eighty one (581) out of 1022 (56.85\%) were aged less than 50 years. The peak incidence was in the 40 - 49 age group (59.69\%). The age range was 20 - 92 years. Of the 1022 women diagnosed of breast cancer, $66.14 \%, 20.35 \%, 7.14 \%$ and $6.36 \%$ were married, single, widowed and divorced respectively. The site of the tumour on presentation was the left breast in $46.57 \%$ and right breast in $53.43 \%$ of cases. Invasive ductal carcinoma (IDC) was the most common breast cancer type diagnosed, accounting for $72.90 \%$, followed by other types of cancers $12.52 \%$. Invasive lobular carcinoma (ILC) was the next breast cancer type identified in the study, representing $1.37 \%$ of the total diagnosis. There was no data for $13.21 \%$ of the women.

Breast feeding, late menarche, contraceptive usage, and time interval between age at menarche and age at menopause were seen as variables decreasing the risk of breast cancer development. Later age at menopause on the other hand increased the risk of breast cancer development. These variables were statistically significant. Parity, family history and age at first child although increased the risk of breast cancer development, they were found to be insignificant variables.

\subsection{Tumour Characteristics}

Lump size on presentation in $71.28 \%$ of the women was $2-5 \mathrm{~cm}, 4.46 \%$ had $<2 \mathrm{~cm}$ tumours and in $24.26 \%$ tumour size was $>5 \mathrm{~cm}$. Axillary lymph node involvement was found in $90 \%$ of the women diagnosed with breast cancer when first seen by a physician; $89.20 \%$ had axillary lymph nodes of more than $25 \%$ involvement.

\subsection{Clinical Stage}

At the time of diagnosis $14.47 \%$ of the women had stage 0 \& I, 33.17\% were stage II, $47.16 \%$ stage III and 5.20\% stage IV. In all, 52.35\% presented in the advanced stage (III and IV) whiles early stage presentation involved $47.65 \%$ of the women. Furthermore $57.76 \%$ of the patients with advanced disease were aged less than 50 years.

Tumour grade: The majority (80.72\%) were grade 2, followed by grade $3(11.35 \%)$ and grade $1(7.93 \%)$.

There was information on hormone receptors for 309 women. Furthermore, there was information on 116 (37.54\%) of the patients on HER2/neu protein receptors. Consistent with previous publication [26] [27], breast cancer subtypes were defined as luminal A (ER positive and PR positive, HER2 negative), luminal B (ER positive and PR positive, HER2 positive), basal-like (ER negative, PR negative, HER2 negative) and HER2 type (HER2 positive, ER negative, PR negative). Immunohistochemical analysis revealed that $22.41 \%$, $24.14 \%$, and $13.79 \%$ of tumors were positive for ER, PR, and HER2, respectively. Only $24.14 \%$ were luminal A or B, and 9.48\% were HER2-positive/ER-negative subtype. Basal-like or triple negative breast cancer was identified in $66.38 \%$ of the cases with complete information on ER, PR and HER2 status (Table 1).

The Kaplan-Meier curve for overall survival by tumor subtype is shown in Figure 1. Subjects with the triple negative subtype, ER/PR and HER2-neagive, had the worst overall survival of $50.80 \%$ as compared with the other subtypes. Subjects in Luminal B had the best survival of 84.42\% (Table 2).

\subsection{Survival Analysis}

A survival analysis was conducted in relation to the following factors: tumour size, lymph node involvement, clinical stage, tumour grade, body mass index and age. Survival analysis showed 390 cancer-related deaths (38.16\%) among the 1022 subjects in the study. The mean survival time was 4.59 years (55.13 months). The 5-year overall survival was $47.9 \%$. The survival curve is shown in Figure 2.

Table 1. Some clinicopathologic characteristics by subtypes.

\begin{tabular}{cccc}
\hline Tumour Subtype & Frequency & \% Frequency & Group \\
\hline $\mathrm{ER}^{+} / \mathrm{PR}^{+} / \mathrm{HER}^{-}$ & 22 & $18.97 \%$ & Luminal A \\
$\mathrm{ER}^{+} / \mathrm{PR}^{+} / \mathrm{HER}^{+}$ & 4 & $3.45 \%$ & Luminal B \\
$\mathrm{ER}^{-} / \mathrm{PR}^{-} / \mathrm{HER}+$ & 11 & $9.48 \%$ & Her 2 Type \\
$\mathrm{ER}^{-} / \mathrm{PR}^{-} / \mathrm{HER}^{-}$ & 77 & $66.38 \%$ & Triple Negative \\
\hline
\end{tabular}


Table 2. Five-year overall survival by tumour subtype and ER/PR status.

\begin{tabular}{rcc}
\hline Subtype & Overall Survival & $95 \%$ CI \\
\hline Luminal A & $59.48 \%$ & $50.57-68.38$ \\
Luminal B & $84.42 \%$ & $72.25-96.58$ \\
Triple Negative & $50.80 \%$ & $31.50-67.20$ \\
\hline
\end{tabular}

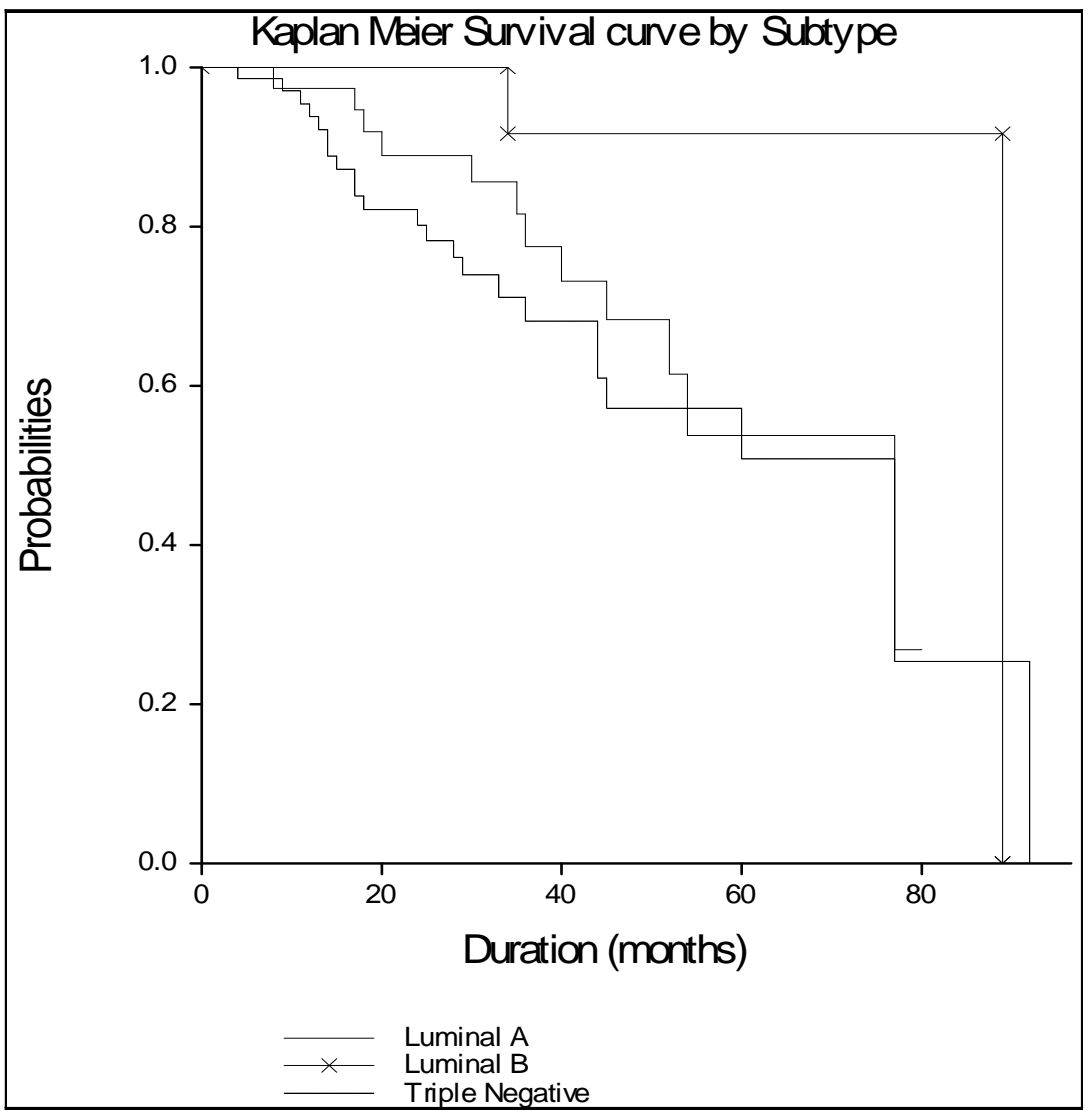

Figure 1. Kaplan meier survival cure by subtypes.

In lymph node involvement of less than or equal to 25\%, cumulative survival was $63.26 \%$ for 52 months (4.33 years). Lymph node involvement of more than $25 \%$ at diagnosis gave 5-year cumulative survival of 46.03\%. The Log rank test indicates significant differences between the two groups. Cumulative survival for cases diagnosed with lump size 2 - $5 \mathrm{~cm}$, was $52.30 \%$ and for lump size $>5 \mathrm{~cm}$, the rate was 33.31\%.

Cancer staging was done using the American Joint Committee on Cancer (AJCC) 2002 system. Among 148 cases diagnosed in stage 0 \& I, cumulative survival was $91.94 \%$ and for the 339 cases diagnosed in stage II, $59.93 \%$. The 428 stage III cases had a rate of 33.95\% and for the 53 stage IV cases, 15.09\%. Breast cancer mortality was correlated to the stage at diagnosis. Testing equality among the groups, p value of 0.000 for both tests indicated significance (Table 3).

The tumours studied were graded using the modified Bloom-Richardson system. Tumour grade 1 had 5-year cumulative survival rate of $49.32 \%$, grade 2 was $48.83 \%$ and grade $3,40.87 \%$. A difference among tumour grades was not significant. Further analysis showed no significant difference between the age groupings as far as survival was concerned. The survival rate was $48.05 \%$ for women less than 50 years and $47.98 \%$ for age group 50 and above, supported by the test statistic with p-values above the 0.05 significance level. A 5-year survival for histological types indicated that, there was a significant difference in survival rates of $42.95 \%$ for patients diagnosed with IDC as compared to $65.03 \%$ for other breast cancer types. 


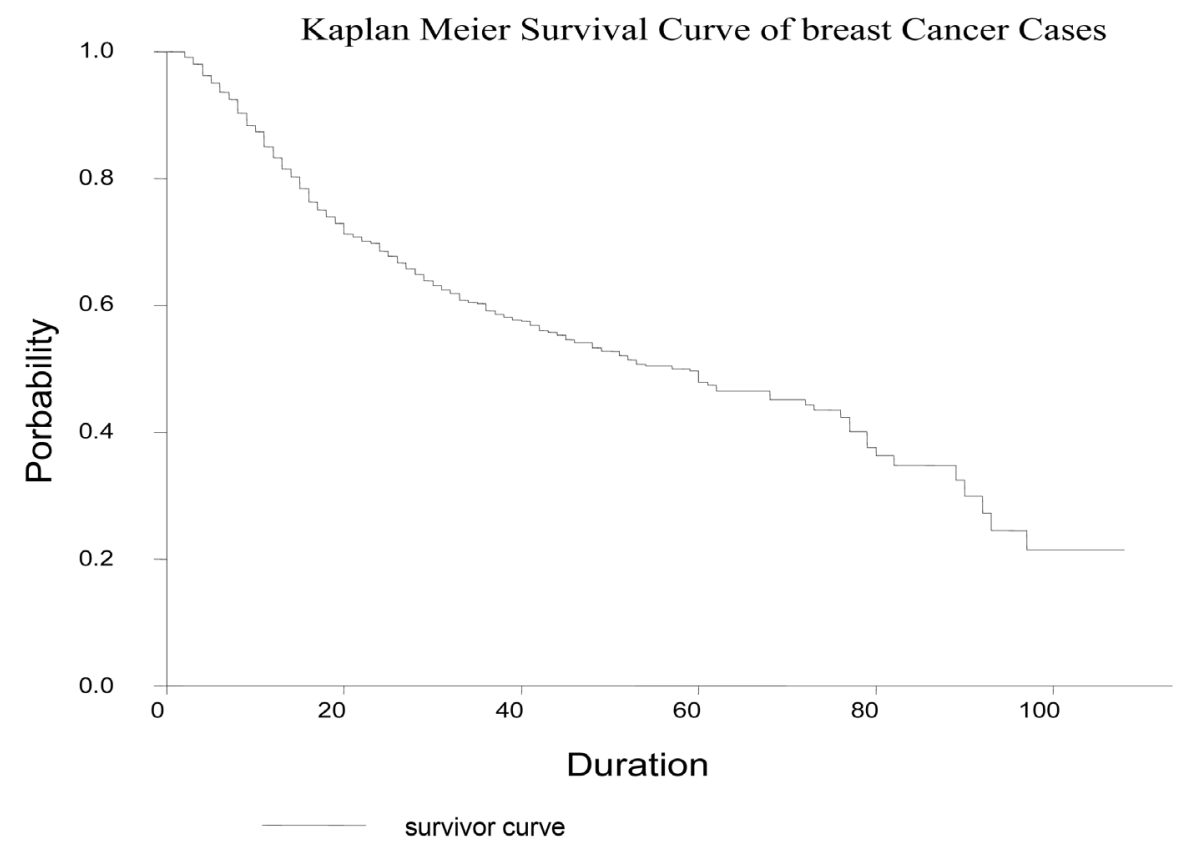

Figure 2. Kaplan Meier survival curve for breast cancer cases.

Table 3. Multivariate 5-year survival analysis of the breast cancer patients.

\begin{tabular}{|c|c|c|c|c|c|}
\hline \multirow{2}{*}{ Variables } & \multirow{2}{*}{$\begin{array}{c}\text { Breast } \\
\text { Cancer cases }\end{array}$} & \multirow{2}{*}{$\begin{array}{l}\text { Breast Cancer } \\
\text { survivors }\end{array}$} & \multirow{2}{*}{ Survival rate } & \multicolumn{2}{|c|}{ Test of Equality } \\
\hline & & & & Log rank & Wilcoxon \\
\hline Axillary Node (AN) & & & & $7.4(0.0064)$ & $7.0(0.0081)$ \\
\hline $0=(\leq 25 \%)$ & 110 & 86 & & & \\
\hline $1=(>25 \%)$ & 912 & 546 & 46.03 & & \\
\hline Tumour Size (TS) & & & & $19.13(0.0001)$ & $14.038(0.0009)$ \\
\hline $0=<2 \mathrm{~cm}$ & 47 & 34 & - & & \\
\hline $1=2-5 \mathrm{~cm}$ & 714 & 462 & 52.3 & & \\
\hline $2=>5 \mathrm{~cm}$ & 261 & 136 & 33.31 & & \\
\hline Stage (ST) & & & & $133.18(0.000)$ & $103.21(0.000)$ \\
\hline $0=0 \& \mathrm{I}$ & 148 & 142 & 91.94 & & \\
\hline $1=\mathrm{II}$ & 339 & 238 & 59.93 & & \\
\hline $2=\mathrm{III}$ & 482 & 247 & 33.95 & & \\
\hline $3=\mathrm{IV}$ & 53 & 5 & 15.09 & & \\
\hline Tumour Grade & & & & $2.00(0.367)$ & $0.435(0.805)$ \\
\hline 1 & 81 & 51 & 49.32 & & \\
\hline 2 & 825 & 515 & 48.83 & & \\
\hline 3 & 116 & 66 & 40.87 & & \\
\hline
\end{tabular}

\subsection{Proportional Hazard Model}

The Cox proportional hazard model is estimated in this section and the effects of covariates on survival are presented in terms of hazard ratios.

From Table 4, three variables met the 0.05 criterion for statistical significance: tumour size, stage at first 
Table 4. Cox regression analysis of 5-year survival for all patients by prognostic factors.

\begin{tabular}{ccccccc}
\hline Variable & DF & B & Standard Error & $\chi^{2}$ & p value & $e^{\beta}$ \\
\hline TS & 1 & 0.39 & 0.177 & 4.84 & 0.028 & 1.48 \\
Age & 1 & 0.0005 & 0.008 & 0.004 & 0.947 & 1.00 \\
ST & 1 & 0.488 & 0.126 & 15.04 & 0.000 & 1.63 \\
GR & 1 & 0.203 & 0.205 & 0.98 & 0.322 & 1.23 \\
AN & 1 & 0.932 & 0.421 & 4.911 & 0.027 & 2.54 \\
\hline
\end{tabular}

diagnosis and axillary node involvement. The estimated hazard ratio $e^{\beta}$ is the expected survival time for the groups. Thus, controlling for other covariates, the expected time for one diagnosed of an advanced stage breast cancer to die was $63 \%$ greater than for those in the early stage. The expected time to die for those with tumour size greater than $5 \mathrm{~cm}$ was $48 \%$ greater than those with tumour size less than or equal to $5 \mathrm{~cm}$. For axillary node involvement, the risk of death was $154 \%$ higher for those with more than $25 \%$ node involvement than those with $25 \%$ or less involved. Age at diagnosis has no effect on survival or death of the patient. This is due to the hazard ratio being equal to 1 . Thus the risk of dying is assumed to be the same for all ages at diagnosis. This result is supported at $5 \%$ level of significance. From the results women with higher tumour grading faces a $23 \%$ ( 0.322 ) higher risk of dying than those with lower tumour grade.

\section{Discussion}

The mean age of breast cancer patients from the study was 47.97 years, consistent with another study from the subregion [28]. The age range was 20 - 92, with the highest incidence occurring in age group 40 - 49 years, consistent with previous studies from Ghana [9]. This indicates that, that Ghanaian women present breast cancer at a significantly younger age as compared to women in the developed world [29] [30].

A survival analysis showed 390 cancer-related deaths (38.16\%) among the 1022 subjects in the study. The overall survival for all subjects was $47.91 \%$ after 5 years which is consistent with a previous study [31] in India. In England women diagnosed with breast cancer in 2001 to 2006 had a five-year survival rate of 82\% [21]. According to US Department of Health and Human Services (2009-2010), five year survival rate was $91 \%$ and $78 \%$ for white women and African American women respectively [22]. Tumour size was found to be a significant variable with a p value of 0.0001 . The expected time to die for those with tumour size greater than $5 \mathrm{~cm}$ is $48 \%$ greater than those with tumour size less than or equal to $5 \mathrm{~cm}$. Thus the smaller the tumour size the better the prognosis. With lymph node involvement, there was a significant difference between the two groups at $\mathrm{p}=$ 0.0003 . The hazard ratio was 2.54 , meaning the risk of death was $154 \%$ higher for those with more than $25 \%$ node involvement as against those with $25 \%$ or less involvement.

Data relating to the clinical stages of breast cancer on first diagnosis showed that $52.35 \%$ of the women presented at the advanced stages (III and IV) whiles early stage presentation involved $47.65 \%$. This is consistent with some studies done in Ghana [9] [32] [33] and Africa [34] [35]. Breast cancer mortality was found to be correlated to the stage at diagnosis. Testing equality among the groups, at a p value of 0.000 indicated significance. Considering the staging in terms of early and advanced, gave a hazard ratio of 1.63 . Thus, controlling for other covariates, the expected time to death for breast cancer patients who were diagnosed with advanced stage cancer was $63 \%$ greater than those with early stage. Differences among tumour grading were not significant as the $\mathrm{p}$ value was 0.3667 from Log rank statistics. From the results, women with higher tumour grading faced a $22.50 \%$ higher risk of dying than those with lower tumour grade. However the results were not supported at $5 \%$ significant level.

Age at diagnosis has no effect on survival or death of the patient according to the study. This was due to the hazard ratio being equal to 1 . Thus the risk of dying was assumed to be the same for all ages at diagnosis. 5-year survival for histology indicated that, there was a significant difference in survival rates of $42.95 \%$ for patients diagnosed with IDC as compared to $65.03 \%$ for other breast cancer types. The implication is that, a woman diagnosed of a cancer type other than IDC, has a better chance of surviving five years or more.

Triple negative breast cancer was identified in $66.38 \%$ of the cases with complete information on ER, PR and HER2 status, which is consistent with earlier studies done. Breast cancer in African women tend to be the ag- 
gressive triple negative subtype, [24] [36] similar to those observed in African-American women in the US, and is non-responsive to commonly used therapeutic drugs.

\section{Conclusions}

Women with bigger tumour size faced a higher risk of dying than the risk faced by those with smaller tumour size. The study's results indicate that early stage breast cancer patients suffer a lower risk of death than the risk suffered by advanced stage breast cancers. As a component of cancer staging, axillary node proved to be a significant predictor of survival with more than $25 \%$ involvement having less chance of survival. Age failed to explain the survival differences of the women. Contrary to the view that tumour grade has a positive influence on survival, the results from this study showed that tumour grade was an insignificant variable. There was a significant difference in survival rates for patients diagnosed with IDC (who faced a lower risk of survival) compared to patients with other breast cancer types. Again $47.91 \%$ of the women will survive after 5 years of being diagnosed with the disease.

The study reinforces the urgent need for improved screening techniques for early detection, and for an aggressive health education campaign to increase the awareness of women in Ghana about the potential risk of breast cancer and early detection by regular testing.

\section{Acknowledgements}

We are thankful to the radiotherapy staff of the Korle-bu Teaching Hospital, who provided us with all the materials that we required for this study and for giving us the permission to browse through the files for the collection of the data. We also would like to acknowledge Messers E. Enchil, Philip Oduro, Isaac Aidoo and Mr. Asihene for their devoted work during data collection.

\section{Limitations of Study}

Many of the cases in our study had incomplete data related to clinical staging, tumour characteristics and hormone receptors. There is clearly a need to improve documentation of clinical data in patients' medical records. Survival analysis did not take into account any form of treatment (surgery, radiotherapy, neoadjuvant and adjuvant chemotherapy and herceptin. Another limitation is that we did not include proliferation index Ki 67 in the subtypes of breast cancer because the information was not available.

\section{Competing Interests}

The authors or our various institutions have no conflicts of interest which includes financial or personal relationships.

\section{Author's Contribution}

Dr. Alice C. Mensah: Defining the Concept and Research Design; Literature search; Data acquisition and analysis; Manuscript preparation, review, editing and submission Dr. Joel Yarney: Defining the Concept and Research Design; Literature search; Data acquisition and analysis; Manuscript preparation, review and editing. Prof. Kaku S. Nokoe: Defining the Concept and Research Design; Literature search; Data acquisition and analysis; Manuscript preparation, review and editing. Dr. Samuel Yaw Opoku: Defining the Concept and Research Design; Literature search; Data acquisition and analysis; Manuscript preparation, review, editing and submission Dr. JN Clegg-Lamptey: Defining the Concept and Research Design; Literature search; Data analysis; Manuscript, preparation, review and editing All the authors read and approved the final version of the manuscript.

\section{References}

[1] American Cancer Society (2008) Cancer Facts and Figures.

[2] Wiredu, E.K. and Armah, H.B. (2006) Cancer Mortality Patterns in Ghana: A 10-Year Review of Autopsies and Hospital Mortality. BMC Public Health, 6, 159-165. http://dx.doi.org/10.1186/1471-2458-6-159

[3] Badoe, E.A. and Baako, B.N. (2000) The Breast. In: Badoe, E.A., Archampong, E.Q. and da Rocha-Afodu, Eds., Principles and Practice of Surgery including Pathology in the Tropics, Department of Surgery, University of Ghana Medi- 
cal School, Accra, 449-477.

[4] Biritwum, R.B., Gulaid, J. and Amaning, A.O. (2000) Pattern of Diseases or Conditions Leading to Hospitalisation at the Korle Bu Teaching Hospital. Ghana Medical Journal, 34, 197-205.

[5] Yaw, O.S., Benwell, M. and Yarney, J. (2012) Knowledge, Attitudes, Beliefs, Behaviour and Breast Cancer Screening Practices in Ghana, West Africa. Pan African Medical Journal, 11, 28.

[6] Gukas, I.D., Jennings, B.A., Mandong, B.M., Igun, G.O., Manasseh, A.N., Ugwu, B.T. and Leinster, S.J. (2005) Clinicopathological Features and Molecular Markers of Breast Cancer in Jos Nigeria. West African Journal of Medicine, 24, 209-213.

[7] Amir, H., Azizi, M.R., Makwaya, C.K. and Jessani, S. (1997) TNM Classification and Breast Cancer in an African Population: A Descriptive Study. Central African Journal of Medicine, 43, 357-359.

[8] Hassan, I., Onukak, E.E. and Mabogunje, O.A. (1992) Breast Cancer in Zaria, Nigeria. Journal of the Royal College of Surgeons of Edinburgh, 37, 159-161.

[9] Clegg-Lamptey, J.N.A. and Hodasi, W.M. (2007) A Study of Breast Cancer in Korle Bu Teaching Hospital: Assessing the Impact of Health Education. Ghana Medical Journal, 41, 72-77.

[10] Mbonde, M.P., Amir, H., Mbembati, N.A., Holland, R., Schwartz-Albiez, R. and Kitinya, N. (1998) Characterizations of Benign Lesions and Carcinomas of the Female Breast in a Sub-Saharan African Population. Pathology, Research and Practice, 194, 623-629. http://dx.doi.org/10.1016/S0344-0338(98)80097-6

[11] Anim, J.T. (1993) Breast Cancer in Sub-Saharan African Women. African Journal of Medicine \& Medical Sciences, 22, 5-10.

[12] Ghartey, F.N. (2001) A Cross-Sectional View of Breast Cancer in Ghana. Mammocare, Ghana.

[13] NCRNM (2007) Annual Report National Center for Radiotherapy and Nuclear Medicine. Korle Bu Teaching Hospital, Ghana.

[14] Beadle, G.F., Harris, J.R., Silver, B., Botnick, L. and Hellman, S.A.H. (1984) Cosmetic Results Following Primary Radiation Therapy and Adjuvant Chemotherapy for Early Breast Cancer. Cancer, 54, 2911-2918. http://dx.doi.org/10.1002/1097-0142(19841215)54:12<2911::AID-CNCR2820541216>3.0.CO;2-V

[15] Sedmak, D.D., Meineke, T.A., Knechtges, D.S. and Anderson, J. (1989) Prognostic Significance of Cytokeratin-Positive Breast Cancer Metastases. Modern Pathology, 2, 519-520.

[16] American Cancer Society. Cancer Facts \& Figures for Hispanics/Latinos 2009-2011.

[17] Alero, F. and Newman, L.A. (2005) Breast Cancer in Sub-Saharan Africa: How Does It Relate to Breast Cancer in African-American Women? Cancer, 103, 1540-1550. http://dx.doi.org/10.1002/cncr.20978

[18] Ly, M., Antoine, M., André, F., Callard, P., Bernaudin, J.F. and Diallo, D.A. (2011) Breast Cancer in Sub-Saharan African Women: Review. Bulletin du Cancer, 98, 797-806.

[19] Corazziari, I., Quinn, M.J. and Capoccaccia, R. (2004) Standard Cancer Patient Population for Age Standardising Survival Ratios. European Journal of Cancer, 40, 2307-2316. http://dx.doi.org/10.1016/j.ejca.2004.07.002

[20] Coleman, M.P., Quaresma, M., Berrino, F., et al. (2008) Cancer Survival in Five Continents: A Worldwide Population-Based Study (CONCORD). The Lancet Oncology, 9, 730. http://dx.doi.org/10.1016/S1470-2045(08)70179-7

[21] Richard, M.A. (2008) Trends and Inequalities in Survival for 20 Cancers in England and Wales 1986-2001: Population-Based Analyses and Clinical Commentaries. British Journal of Cancer, 99, S1.

[22] The US Department of Health and Human Services (2009-2010).

[23] Kirby, A. (2005) Early Detection of Breast Cancer in Ghana, West Africa. Journal of Investigative Medicine, 53, 580.

[24] Sark, A., Kleer, C.G., Martin, I., Awuah, B., Nsiah-Asare, A., Takyi, V., Braman, M.E., Quayson, S., Zarbo, R., Wicha, M. and Newman, L. (2010) African Ancestry and Higher Prevalence of Triple-Negative Breast Cancer. Cancer, 116, 4926-4932. http://dx.doi.org/10.1002/cncr.25276

[25] Mayo, R. and Hunter, A. (2003) Fatalism toward Breast Cancer among the Women of Ghana. Healthcare for Women International, 24, 608-616. http://dx.doi.org/10.1080/07399330390217752

[26] Carey, L.A., Perou, C.M., Livasy, C.A., et al. (2006) Race, Breast Cancer Subtypes, and Survival in the Carolina Breast Cancer Study. JAMA, 295, 2492-2502. http://dx.doi.org/10.1001/jama.295.21.2492

[27] Yang, X.R., Sherman, M.E., Rimm, D.L., et al. (2007) Differences in Risk Factors for Breast Cancer Molecular Subtypes in a Population-Based Study. Cancer Epidemiology, Biomarkers \& Prevention, 16, 439-443. http://dx.doi.org/10.1158/1055-9965.EPI-06-0806

[28] Anyanwu, S.N. (2000) Breast Cancer in Eastern Nigeria: A Ten Year Review. West African Journal of Medicine, 19, 120-125.

[29] Adebamowo, C.A. and Ajayi, O.O. (2000) Breast Cancer in Nigeria. West African Journal of Medicine, 19, $179-191$. 
[30] Bowen, R.L., Duffy, S., Ryan, W.D.A., Hart, I.R. and Jones, J.L. (2008) Early Onset of Breast Cancer in a Group of British Black Women. British Journal of Cancer, 98, 277-281. http://dx.doi.org/10.1038/sj.bjc.6604174

[31] Gajalakshmi, C.K. (1997) A Population-Based Survival Study on Female Breast Cancer in Madras, India. British Journal of Cancer, 75, 771-775. http://dx.doi.org/10.1038/bjc.1997.137

[32] Asumanu, E., Vowotor, R. and Naaeder, S.B. (2000) Pattern of Breast Diseases in Ghana. Ghana Medical Journal, 34, 206-209.

[33] Anim, J.T. (1979) Breast Cancer in Accra. Ghana Medical Journal, 18, 161-167.

[34] Boder, J.M.E., Abdalla, F.B.E., Elfageih, M.A., Abusaa, A., Buhmeida, A. and Collan, Y. (2011) Breast Cancer Patients in Libya: Comparison with European and Central African Patients. Oncology Letters, 2, 323-330.

[35] Ikpatt, O.F., Kuopio, T. and Collan, Y. (2002) Proliferation in African Breast Cancer: Biology and Prognostication in Nigerian Breast Cancer Material. Modern Pathology, 15, 783-789. http://dx.doi.org/10.1097/01.MP.0000021764.03552.BD

[36] Yarney, J., Vanderpuye, V. and Clegg Lamptey, J.N. (2008) Hormone Receptor and HER-2 Expression in Breast Cancers among Sub-Saharan African Women. The Breast Journal, 14, 510-511. http://dx.doi.org/10.1111/j.1524-4741.2008.00636.x

\section{Abbreviations}

AJCC: American Joint Committee on Cancer

ER: Estrogen Receptor

HER2: Human Epidermal growth factor Receptor 2

PR: Progesterone Receptor

IDC: Invasive Ductal Carcinoma

ILC: Invasive lobular carcinoma

KBTH: Korle-Bu Teaching Hospital 


\section{Appendix A}

Table A1. Descriptive statistics of some risk factors for all the women.

\begin{tabular}{ccccccc}
\hline All women = 2397 & AG & AFC & MN & MP & PT & APM \\
Minimum & 20 & 12 & 9 & 25 & 0 & 8 \\
Mean & 43.51 & 23.83 & 15.17 & 47.55 & 2.47 & 32.38 \\
Median & 43 & 24 & 15 & 48 & 2 & 33 \\
IQR & 18 & 5 & 2 & 0 & 3 & 4 \\
Maximum & 92 & 46 & 26 & 60 & 12 & 45 \\
Standard Dev. & 12.72 & 4.7 & 2.03 & 3.55 & 2.31 & 4 \\
Skewness & 0.34 & 0.72 & 0.65 & -1.47 & 0.89 & -1.21 \\
Kurtosis & -0.17 & 1.6 & 3.17 & 5.71 & 0.8 & 3.78 \\
\hline
\end{tabular}

AG—Age at first visit, AFC—Age at first child, MP—Age at Menopause, APM—Age interval between Menarche and Menopause, MN—Age at Menarche, PT—Parity.

Table A2. Schedule for breast cancer patients.

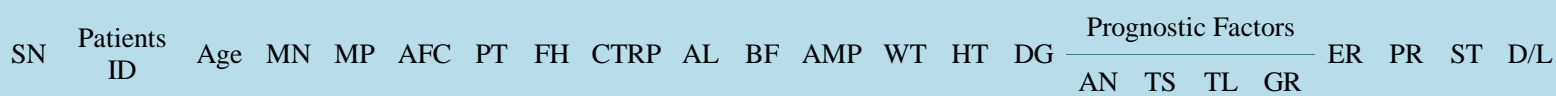

